\title{
A estrutura como logos da experiência pré-reflexiva*
}

The structure as logos of pre-reflective experience

\author{
**Ericson Sávio Falabretti
}

Resumo: Este trabalho examina o sentido da noção de estrutura na obra Fenomenologia da Percepção. Discute, primeiramente, como a Fenomenologia da Percepção, ao liberar a estrutura do fisicalismo, promove uma verdadeira renovação filosófica desse conceito. Depois, numa perspectiva complementar, apresenta a ideia de estrutura como um conceito chave no interior da Fenomenologia a partir de três perspectivas interiormente integradas no campo fenomenal: a estrutura como percepção, como presença e temporalidade. Esses dois motivos, como se pretende indicar, formam o núcleo de uma filosofia da estrutura aberta no interior do pensamento fenomenológico.

Palavras-chave: Estrutura. Percepção. Corpo. Espaço. Tempo.

\begin{abstract}
This paper examines the meaning of the notion of structure in the work Phenomenology of Perception. Discusses, first, as the Phenomenology of Perception, by releasing the structure of physicalism, promotes a true renewal of this philosophical concept. Then, in a complementary perspective, presents the idea of structure as a key concept within the Phenomenology from three integrated perspectives within the phenomenal field: the structure as perception, such as the presence and temporality. These two reasons, as it is intended to indicate, form the core of a philosophy of open structure within the phenomenological thought.
\end{abstract}

Keywords: Structure. Perception. Body. Space. Time.

* O desenvolvimento do artigo está vinculado a um projeto de pesquisa financiado pela CAPES e pela PUCPR.

* * Professor do Programa de Pós-Graduação em Filosofia da PUCPR. E-mail: <efalabretti@ gmail.com>.

\begin{tabular}{|l|l|l|l|l|l|}
\hline Veritas & Porto Alegre & v. 58 & n. 2 & maio/ago. 2013 & p. 371-398 \\
\hline
\end{tabular}




\section{Introdução}

O tema da estrutura percorre todos os momentos da obra de MerleauPonty. É central nos seus dois primeiros livros, ainda que a importância e a especificidade dessa ideia no interior da $\mathrm{PHP}^{1}$ esteja longe de ser reconhecida pela crítica. Reaparece nos textos sobre Linguagem, Filosofia e nos Cursos dos anos 50 - fundamentalmente a partir das leituras de Saussure e Lévi-Strauss - e, finalmente, a estrutura é retomada como gestalt no VI enquanto conceito chave de uma nova ontologia que ultrapassaria todos os dualismos, no qual o sentiente e o sentido formariam um único tecido: "O meu corpo é uma Gestalt e é co-presente em toda Gestalt." (M-P, p. 193, 1999b).

Apresentar todo esse itinerário da noção de estrutura na obra de Merleau-Ponty exigiria o fôlego de um livro - por isso mesmo, o objetivo do presente trabalho concentra-se sobre o uso e o sentido dessa noção no interior da $P H P$, um pouco esquecida como já vimos acima. ${ }^{2} \mathrm{~A}$ centralidade

1 Abreviaturas: PHP (Fenomenologia da Percepção); SC (Estrutura do Comportamento); VI (Visível e Invisível); M-P (Merleau-Ponty).

2 O tema da estrutura tem rendido excelentes trabalhos sobre a filosofia de MerleauPonty, que não apenas iluminam problemas e questões interiores à sua obra, mas, também, remetem a discussões sobre a relação entre fenomenologia, ciências humanas e a própria filosofia estruturalista. Todavia, de modo geral, o que encontramos são análises muito bem realizadas sobre o papel da estrutura como modelo de percepção, presente na primeira obra de Merleau-Ponty, nos textos intermediários e, ainda, como parte essencial e incompleta de uma nova ontologia do VI. Sem querer aqui, nessa breve nota, resumir todos os trabalhos sobre esse problema, vale a pena destacar, primeiro, a obra de filósofo italiano Andrea Bonomi. Bonomi retoma, entre outros pontos, o debate da obra merleau-pontyana, sobretudo, com a Teoria da Gestalt, Saussure e Lévis-Strauss. Para Bonomi, de modo geral, via esses autores e escolas, o estruturalismo permitira interpretar o sentido fenomenológico de alguns conceitos basilares como experiência bruta, percepção etc. Outro trabalho que merece destaque é o belo estudo de Marilena Chaui (In: Experiência do Pensamento: Ensaios sobre a obra de MerleauPonty, São Paulo, Martins Fontes, 2002). Concentrado no debate no qual o pensamento de Merleau-Ponty desloca-se da Teoria da Gestalt para as Ciências Humanas, Chaui retoma com propriedade, entre outras ideias, o sentido histórico que emerge na obra merleau-pontyana. Esse trabalho de Chaui, alimentado pela brilhante intuição de ligar a discussão da $S C$ aos textos posteriores, é uma paragem obrigatória para todos que pretendem compreender o sentido de história que nasce da obra de Merleau-Ponty. Também vale a pena destacar o texto de Barbaras sobre estrutura, comentado ao longo desse artigo, que concebe a centralidade do conceito na obra de Merleau-Ponty, ainda que Barbaras, a exemplo dos demais, não estenda essa centralidade para a PHP. Mais recentemente, David Scarso tem se dedicado com muita competência ao problema da estrutura na obra de Merleau-Ponty. Além da sua tese de doutoramento (Merleau-Ponty e Lévi-Strauss: Reconstrução de um diálogo sobre filosofia e Ciências Humanas), em que ele recupera o cenário estruturalista com o qual Merleau-Ponty envolveu-se, tem publicado diversos trabalhos sobre o tema da estrutura na obra de Merleau-Ponty e a sua relação, principalmente, com Lévis-Straus e Sartre. Além disso, vale a pena destacar os artigos de Reinaldo Furlan e Marcos Sacrini Ferraz publicados sobre esse tema no 
da estrutura na PHP justifica-se por dois motivos. Primeiro, a PHP liberta a estrutura de todo fisicalismo e realismo das formas pelos quais ela havia sido descrita na Teoria da Gestalt e, nessa importante direção, indica uma renovação filosófica do conceito de Gestalt que ainda não estava presente na SC. Depois, numa perspectiva complementar, a percepção e o esquema corporal somente podem ser descritos como estruturas, e a própria estrutura encontraria nesses dois aspectos o sentido preciso da sua renovação. Esses dois motivos formam o núcleo de uma filosofia da estrutura aberta no interior do pensamento fenomenológico, isso alguns anos antes da filosofia estruturalista ocupar a cena principal das cátedras e do pensamento francês.

Merleau-Ponty, na SC, concebe a ideia de estrutura a partir dos trabalhos da Teoria da Gestalt - fundamentalmente de Köhler e de Kofka - e das pesquisas do neuro-fisiologista alemão Goldstein. A estrutura, pensada desde o início sob o paradigma figura e fundo, confronta os princípios basilares das teorias científicas do comportamento - o localizacionismo e a hipótese de constância - e, o mais importante, as teses reducionistas sobre corpo e a velha ideia de percepção como síntese de sensações.

Na obra The organism, Goldstein (p. 99, 1995) estabelece que cada movimento de uma parte do corpo "é acompanhado por uma mudança na postura do resto do corpo." O que está em jogo no corpo são fenômenos de estrutura. Uma reação específica, seja na forma de um reflexo ocular ou de uma extensão plantar, por exemplo, é estendida a todo organismo, pois a percepção de um determinado ponto do organismo é sentida em função da sua implicação configuracional como o todo, uma relação que relembra as pesquisas da Gestalt sobre a estrutura figura e fundo: "Quando analisamos a estrutura dos atos ou desempenhos, encontramos esta mesma configuração. Por isso, estou inclinado a considerar esta configuração de excitação, a relação figura-fundo, como a forma básica do funcionamento do sistema nervoso." (GOLDSTEIN, p. 101, 1995). Goldstein estende o modelo explicativo da percepção inaugurado pela

número especial da revista Dois Pontos (v. 5, n. 1, 2008). Enquanto Ferraz, no texto Sujeito perceptivo e mundo em MerleauPonty, discute as variações do modelo de percepção da obra de Merleau-Ponty, sobretudo a partir de um debate com a obra de Kafka, Furlan apresenta a ideia de que a retomada da noção de estrutura no último Merleau-Ponty está muito mais próxima da psicanálise do que de Lévi-Strauss. (Estrutura e subjetividade no último Merleau-Ponty). Finalmente, no Brasil, merecem destaque os trabalhos de Marcos Muller-Granzotto, se bem que a abordagem de Muller esteja aberta a um campo muito mais amplo que as discussões sobre Merleau-Ponty, como podemos ler no livro (MÜLLER-GRANZOTTO, Marcos José; Rosane Lorena. Fenomenologia e Gestalt-terapia. São Paulo: Summus, 2007. 366p.) 
Teoria da Gestalt para o substrato fisiológico, movimento que MerleauPonty soube bem interpretar no momento em que pensou o corpo próprio.

A análise do caso Schneider, o personagem mais frequente nos textos de Merleau-Ponty, estabelece que relações de conjunto - do tipo figura e fundo -aproximar-se-iam muito mais de uma descrição real do comportamento do que as explicações atômicas que apenas concebem o organismo e o meio como dois termos ligados unicamente por relações causais objetivas. Schneider, paciente de Goldstein, com ferimento de guerra sem sequelas aparentes, apresentava uma série de patologias: distúrbios de percepção, de reconhecimento visual e tátil, de motricidade, de memória, de inteligência e, como está abaixo, distúrbios de linguagem como afasia e alexia. Na descrição de Merleau-Ponty (p. 104, 1999a), tomada de Goldstein, Schneider apresentava-se como:

O sujeito não pode acompanhar um sermão ou um discurso. Fala fluentemente em respostas às solicitações de uma situação concreta; em todos os outros casos tem que preparar antecipadamente as suas frases. Para recitar as palavras de uma canção tem que assumir a postura do cantor. Não pode subdividir em palavras uma frase que acabou de pronunciar e, inversamente, palavras coerentes separadas por uma pausa, nunca constituem para ele uma frase. Não sabe nem soletrar as letras de uma palavra que pronuncia bem como conjunto e nem escrevê-las isoladamente, ao passo que possui a palavra como conjunto motor automático. Isso mostra o quanto a linguagem é nele deficiente, embora essas insuficiências sejam especialmente marcadas na instituição de conjuntos simultâneos.

Duas situações tornam o caso Schneider essencial para os interesses de Merleau-Ponty. Primeiro, todas as patologias apresentadas, mascaradas pela aparência normal de Schneider, não afetavam integralmente as suas funções cognitivas, motoras e de linguagem. Depois, à primeira vista, todas as patologias estavam ligadas a uma única lesão. Como explicar esse complexo de distúrbios tão variado em Schneider? Mais especificamente, como entender a habilidade de Schneider para ler e falar as mesmas palavras somente em determinados contextos? Schneider conseguia ler uma frase, mas, ao mesmo tempo, mostrava-se incapaz de ler isoladamente as palavras que compunham essa oração. Como explicar que patologias de funções aparentemente tão diferentes tenham origem em uma mesma lesão?

As conclusões de Goldstein indicam que os sintomas de linguagem em Schneider são uma resposta do organismo aos problemas do meio e representam uma perturbação no comportamento de conjunto. É preciso considerar, interpreta Merleau-Ponty (p. 93, 1999a), "que a doença não se refira ao conteúdo do comportamento, mas à sua estrutura e que, em 
consequência, ela não seja alguma coisa que se observa mas que se compreenda". No caso da alexia, por exemplo, o doente não demonstra incapacidade absoluta de ler, mas não consegue ler fora de um contexto específico; a transformação ocorre no sentido de um comportamento menos diferenciado, menos organizado, mais global, mais amorfo e quase totalmente aderente ao meio. Schneider apresenta uma alteração qualitativa, um comportamento que não consegue, em algumas situações, ir ao essencial: apreender um contexto, perceber uma figura sobre um fundo. A doença, portanto, não se refere ao seu conteúdo, mas à sua estrutura, pois a função da linguagem mantém-se quase intacta e Schneider permanece como alguém que fala. Para Goldstein, as deficiências são alterações do comportamento resultantes de distúrbios de estruturas. É o que Goldstein denomina como atitude categorial: "o distúrbio poderá (...) ser definido como incapacidade de captar o essencial de um processo ou enfim como incapacidade de circunscrever nitidamente um conjunto percebido, concebido, ou apresentado, a título de figura em um fundo tratado como indiferente" ( M-P, p. 98, 1999a).

Ao lado de Husserl e de Goldstein é preciso destacar o papel capital da Teoria da Gestalt na formação da obra merleau-pontyana. A Gestalttheorie não apenas reafirmou o campo perceptivo como abertura ao campo fenomenal - o nascido da redução - como já estava dado na obra de Husserl, mas ofereceu um fundamento positivo para os fenômenos perceptivos desdobrados no solo pré-reflexivo: a noção de Gestalt (forma ou estrutura).

Para os representantes Gestalttheorie da escola de Berlim, três princípios, de modo geral, explicariam como as formas são apreendidas: como totalidades organizadas; como algo sempre presente num campo; como estruturas percebidas num só golpe, de modo instantâneo. Contudo, enquanto esses três aspectos são mantidos por Merleau-Ponty, uma última concepção basilar de orientação ontológica da Gestalttheorie apresenta-se problemática.

Apesar das formas não serem constituídas pelo sujeito e não serem elementos psicológicos, elas são concebidas pela Gestalttheorie num viés naturalista. Assim, Köhler indica que a Gestalttheorie fundou um princípio mais próximo da experiência direta: o princípio do isomorfismo psicofísico. Köhler demonstra, primeiro, a validade do isomorfismo a partir de uma "lei espacial" que integraria à percepção ao substrato fisiológico: " $A$ ordem experimentada no espaço é sempre estruturalmente idêntica a uma ordem funcional na distribuição dos processos cerebrais ocultos" (p. 5, 1980). Essa lei sustenta, basicamente, a ideia de que uma determinada percepção três pontos brancos numa superfície negra - também seria encontrada nos processos cerebrais. Esse princípio de similaridade também seria 
compatível com o sentido temporal dos fenômenos perceptivos. De modo análogo, o tempo experimentado no campo perceptível deve corresponder a um evento funcional de natureza cerebral: "à ordem constatada pela experiência no tempo é sempre estruturalmente idêntica a uma ordem funcional na sequência dos processos cerebrais correlatos" (KÖHLER, p. 41, 1980). Uma terceira aplicação do princípio psicofísico é enunciada em termos de hipótese fisiológica dos eventos sensoriais. Supõe uma espécie de unidade substancial - de mesma natureza - entre os fenômenos da experiência e os processos fisiológicos: “(...) as unidades da experiência correspondem a unidades funcionais nos processos fisiológicos ocultos" (KÖHLER, p. 41, 1980).

A estrutura para a Gestalttheorie passou a significar a ideia de que o campo fenomenal - a experiência - comporta um substrato psicofísico - a forma - que integraria o físico, o fisiológico e o mental. Resumidamente, para a Gestalttheorie, a noção de forma, fundada nas relações de conjunto e em processos dinâmicos que tendem ao equilíbrio a partir da composição de forças internas e externas, pode ser assim descrita: i) pode ser aplicada ao domínio orgânico e inorgânico; ii) são processos totais cujas propriedades não resultam da soma das propriedades das partes isoladas; iii) existe forma sempre que as propriedades de um sistema modificam-se para cada mudança ocorrida em uma de suas partes; iv) em uma forma, quando todas as partes mudam, conservamse as mesmas relações.

É verdade que a Gestaltheorie rompeu com o psicologismo. Que, evidentemente, cabe-lhe o mérito de ter reconhecido a originalidade e a anterioridade dos fenômenos da percepção diante do mundo objetivo. Foi a Gestalttheorie, desde as primeiras pesquisas de Wertheimer, que buscou compreender como uma forma constitui-se através da percepção. As intervenções de Köhler e de Koffka, com as noções de experiência direta e de meio comportamental, levaram, do mesmo modo, ao fim da "hipótese da constância" e, por consequência, a ideia do juízo como explicação da percepção perdeu definitivamente o seu lugar. Todavia, segundo Merleau-Ponty, a Gestalttheorie não notou o alcance filosófico do retorno à experiência perceptiva e, desse modo, não radicalizou a psicologia das formas em uma filosofia das formas. O princípio do isomorfismo - as estruturas são entes naturais - mostra que a Gestalttheorie manteve-se sempre fiel ao naturalismo e nunca chegou a abandonar efetivamente o realismo, pois faltou à Gestalttheorie realizar, sobretudo, "uma reforma do entendimento (...) recolocar em questão o pensamento objetivo da lógica e da filosofia clássicas, pôr em suspenso as categorias do mundo, pôr em dúvida, no sentido cartesiano, as pretensas evidências do realismo, e proceder a uma verdadeira 'redução fenomenológica'" (M-P, p. 80, 1999a). 
De modo geral, o problema maior do isomorfismo é a redução do campo fenomenal ao físico. As estruturas biológicas e psíquicas, por exemplo, apresentam propriedades formais semelhantes às estruturas físicas, mas nem por isso compartilham a mesma quidade substancial e as mesmas relações de ordem como estabeleceu a Gestalttheorie. É preciso evitar a perspectiva desse realismo fisicalista da Gestalttheorie, pois ao mesmo tempo em que se afasta do vitalismo e do espiritualismo, ela reduz tudo à existência de formas físicas. $\mathrm{E}$ a forma, como interpreta Merleau-Ponty (p.177, 1999a), "não é um elemento no mundo, mas um limite para o qual tende o conhecimento físico que ela próprio define".

Para Merleau-Ponty, a estrutura é fundamental na medida em que supera a antítese entre um comportamento de ordem inferior - simples em oposição a um outro de ordem superior, complexo. O mais importante é considerar a aplicação transversal da estrutura na compreensão dos diferentes campos que operaram nas relações entre consciência e natureza. Em uma bolha de sabão como em um organismo, diz MerleauPonty (p. 205, 2006), "o que se passa em cada ponto é determinado pelo que se passa em todos os outros". Depois, na explicação do comportamento, nunca podemos absolutamente definir aquilo que depende de cada uma das condições externas e internas, do ambiente, do vital e do mental. Desse modo, as acepções explicativas da ordem física, vital e humana, consideradas, respectivamente, quantidade, ordem e significação são, ainda que de forma restritiva, intercambiáveis entre as ordens. A significação, por exemplo, núcleo de sentido privilegiado das formas simbólicas, não deixa de ter um valor objetivo no estudo da vida, como também na compreensão dos sistemas físicos, ainda que em grau decrescente. A teoria das formas integra o campo físico sistema de forças mecânicas orientadas - o campo fisiológico - sistema de tensões e correntes - e, se considerarmos as formas simbólicas, o campo mental. Além disso, a estrutura revela o essencial, o núcleo de sentido em cada campo. Para explicar, por exemplo, um fenômeno físico é preciso compreender os conjuntos que aparecem como totalidade. Num sistema elétrico a totalidade é o equilíbrio de cargas, lido pela consciência como a estrutura desse sistema. Também nesse caso, como sintoma da integração entre as diferentes formas, o equilíbrio não deixaria de operar nas ordens vital e simbólica.

No entanto, nesse ponto, conforme a leitura de Barbaras ${ }^{3}$, falta responder qual seria o sentido das estruturas perceptivas que não são redutíveis nem ao ser natural e nem ao ser vital? Enfim, em que consiste a

CF. Cf. BARBARAS, Merleau-Ponty et la psychologie de la forme, in: Les Études Philosophiques, n. 57, p. 151-163, 2001/2. 
percepção que explicaria a existência como significação? Para responder ao problema do sentido das formas simbólicas - vividas na consciência -, a impressão geral é de que todo processo de significação foi assumido em proveito da consciência perceptiva de inspiração criticista, pois o comportamento superior - a vida da consciência - compreende a ordem física e vital sem reduzir-se a nenhuma delas. As formas física, vital e da consciência são totalidades significativas, mas, por outro lado, MerleauPonty, num primeiro momento, reafirmaria a atitude do transcendental kantiano ao supor que toda totalidade é totalidade para uma consciência.

Segundo Barbaras, Merleau-Ponty contorna o transcendental kantiano, pois, antes de tudo, a significação da forma é imanente à própria forma e, depois, a relação da consciência com esse sentido imanente das estruturas é dialética. A presença da consciência faz-se através do corpo, e toda a significação da vida da consciência é encontrada fora da consciência, isto é, na existência. Contudo, Merleau-Ponty deixou em aberto uma exploração filosófica da estrutura e, portanto, resta saber se, na PHP, ele pensou a Gestalt como parte de uma filosofia da estrutura. Barbaras, no artigo já citado, diz claramente que não. A estrutura permitiu a Merleau-Ponty circunscrever os problemas da percepção diante da tradição. Mas, na medida em que ele não colocou em questão as categorias fundamentais que o próprio Husserl herdou dessa mesma tradição - e aqui Barbaras está se referindo ao papel constituinte do cogito -, ele deixou de explorar plenamente a potencialidade da estrutura.

Descombes, ${ }^{4}$ ao discutir a passagem da fenomenologia ao estruturalismo na França, também mostra que Merleau-Ponty, orientado pela tradição fenomenológica, não levou a cabo uma filosofia da estrutura: restringiu-se a reproduzir essa noção como modelo da percepção, mantendo-se, portanto, no ponto de vista inaugurado pela Gestalt. Nesse caso, é preciso explorar o sentido dessa noção de estrutura retomada pela PHP para, então, determinar se Merleau-Ponty finalmente alcançou a significação filosófica que faltou na primeira obra ou, ao contrário, como bem estabeleceram as leituras de Barbaras $^{5}$ e Descombes, continuou preso às categorias husserlianas - opondo o naturante ao naturado - e voltado para o problema da percepção ainda nos limites de uma filosofia da consciência.

A percepção é o meu acesso primordial ao mundo, é o meu contato permanente com as coisas e com o outro. "Portanto, não é preciso perguntar se nos percebemos verdadeiramente um mundo, é preciso dizer, ao contrário, o mundo é aquilo que nos percebemos" (M-P, p. 14, 1999a).

\footnotetext{
Cf. DESCOMBES, p. 91, 1997.

Cf. BARBARAS, p. 157, 2001.
} 
A tese central da percepção, na PHP, estabelece que percebo a partir da minha condição de ser-no-mundo e que tudo o que percebo apresentase como uma estrutura de sentido dado em um contexto do tipo figura e fundo. Mas o que significa ser-no-mundo e perceber num contexto desse tipo?

Na introdução da PHP, Merleau-Ponty dedica-se a desconstruir as teses do intelectualismo, do empirismo e da psicologia associacionista sobre a sensação de que estão na base do esquecimento da percepção e da nossa presença carnal no campo fenomenal. Mas o que é o sentir na perspectiva merleau-pontyana? Seu significado genuíno está dado no domínio pré-objetivo, onde sentir já é perceber. Esse retorno ao transcendental aberto pela percepção, uma verdadeira redução fenomenológica ao campo da experiência vivida, mostra que as sensações versam sobre relações e não sobre termos absolutos. A pura impressão, sustentada pelo intelectualismo, assim como a qualidade muda do empirismo não são encontradas na experiência vivida que não distingue o sentir e o perceber como dois acontecimentos consequentes. Quando me volto ao testemunho cru dos sentidos, reconheço que é próprio do percebido deixar-se envolver por seu contexto e apresentar-se carregado de significações que independem de uma operação constituinte do cogito. A percepção nunca se reduz a uma experiência fechada, pois toda a percepção apreende um sentido ou uma significação envolta em um campo que permanece aberto; o determinado supõe o indeterminado, assim como o sentido arrasta consigo o não sentido e o visível aloja-se na carne do invisível. O percebido comporta lacunas que não são simples imperfeições e mostra-se desde o seu nascimento como expressão de uma significação nascida de um encontro entre percepiente e o percebido. Pois ver é ver algo, perceber é ter presente um ente de significação estrutural. É isso que nos mostra a experiência do ver diante do dado sensível mais elementar que podemos obter: a relação figura e fundo. Uma análise da estrutura figura e fundo revela que a ambiguidade, nesse caso, não se refere a imperfeições, mas à possibilidade de uma percepção que nunca esgota o próprio percebido ou o ato de perceber. É a própria ambiguidade que passa a ter um caráter positivo e, de modo evidente, estabelece que a percepção não está nem no domínio do percepiente e nem do percebido. A percepção, por um lado, me diz onde estão a figura e o fundo como, por outro lado, não permite distinguir absolutamente onde termina o fundo e começa a figura. A percepção é movimento, é fluxo que oferece, permanentemente, o encontro e o contraste, as zonas de confluência e separação que compõem a estrutura figura e o fundo, conjugando, num mesmo campo de visão, perspectivas opostas que só não permanecem intercambiáveis para um pensamento deslocado do sensível. A figura, 
ao mesmo tempo em que se destaca do fundo, permanece, na mesma situação, ligada a esse fundo, que parece sustentá-la. Essa configuração está no domínio das estruturas, da percepção de um todo, pois a figura e o fundo estão indissoluvelmente presentes desde a abertura da percepção:

Seja uma mancha branca sobre um fundo homogêneo. Todos os pontos da mancha têm em comum uma certa 'função' que faz deles uma 'figura'. A cor da figura é mais densa e como que mais resistente; as bordas da mancha branca lhe 'pertencem' e não são solidárias ao fundo contíguo; a mancha parece colocada sobre o fundo e não o interrompe. Cada parte anuncia mais do que ela contém, e essa percepção elementar já está portanto carregada de um sentido. (M-P, p. 24, 1999a)

A cor do fundo - o vermelho - não é apenas um matiz com qualidades: "quente", "intenso" etc. "Anunciar alguma coisa sem a conter", como o diz texto, é exercer uma função de conhecimento que representa algo que não está somente nas coisas e não é possuído como parte real da minha percepção, mas como parte intencional. Na relação figura e fundo, o percebido está sempre no meio de outra coisa, faz parte de um campo no qual a fronteira entre o visto e o não visto permanece dinâmica.

Para o pensamento objetivo da geometria e da ótica, as imagens das coisas formam-se a cada momento em nossa retina, e tudo aquilo que está fora de um perímetro determinado não age sobre o aparelho da visão e, desse modo, não faz parte do campo visual, não conta e não interfere na visão. Contudo, na consideração da experiência direta do ver, o indeterminado - o não absolutamente visto - é sentido como uma parte essencial não apenas na formação do campo visual, mas na visão da própria coisa vista. Na experiência do ver, o meu campo visual comporta o plenamente visto, como também acolhe os objetos escondidos e embaralhados e arrasta-se até as coisas fugidias e os entes não vistos. Todos formam o meu campo visual, e a diferença entre o plenamente visto e as coisas fugidias remonta tão somente a densidade de presença que cada coisa ocupa no campo perceptível. O problema dessa discrepância entre a teoria objetiva do ver e a experiência do ver está no fato de que aquilo que se passa na retina não é o que ocorre no campo fenomenal. Não vejo, normalmente, os objetos invertidos, não tenho uma experiência da visão com limites e fronteiras precisas e, de modo algum, nunca delimito o ponto exato em que nasce, no meu campo visual, uma paisagem, um carro, uma pessoa ou, de modo geral, uma estrutura. Não é possível estabelecer o momento exato - tempo -, no qual um estímulo deixa de ser visto ou, ainda, definir precisamente - espaço - a região em que a figura destaca-se do fundo: "Não é fácil descrever a região que rodeia 
o campo visual, mas é certo que ela não é nem cinza nem negra" (M-P, p. 27, 1999a). Além disso, o visto não adere aos estímulos, está ligado a um contexto perceptivo que reúne o cogito às coisas: a minha posição, a luz, a distribuição dos objetos, a significação da situação etc.

Portanto, se a visão é sempre "assombrada" por um conjunto de entes não plenamente vistos que fornecem densidade ao campo visual, ela sempre será visão de uma estrutura que não é realizada por elementos a priori na consciência ou, ainda, por operações lineares desencadeadas no substrato fisiológico. Uma descrição pura da minha experiência perceptiva supõe que a estrutura não está antes e nem fora da percepção: "A boa forma não é realizada porque ela seria boa em um céu metafísico, ela é boa porque está realizada em nossa experiência" (M-P, p. 40, 1999a). A unidade do percebido é autóctone e originária, precede todas as operações que a determinariam segundo a lógica do pensamento objetivo. As normas da associação - contiguidade, semelhança de projeção de imagens, de recordação - não formam a percepção, mas nascem dela: "É portanto sob o meu olhar atual que nascem o cavalo, o gato, a palavra substituída, o relevo" ( M-P, p. 45, 1999).

A Figura sobre um fundo, portanto, contém muito mais qualidades do que aquelas atualmente dadas. Se a figura tem contornos que não pertencem ao fundo e, ao mesmo tempo, desprendem-se do fundo, ele, por sua vez, é ilimitado e de cor incerta, continua sob a figura. As partes do conjunto possuem um sentido particular. A figura depende do fundo sobre o qual aparece e o fundo serve como uma estrutura, uma espécie de moldura sem traços e ângulos precisos que acolhe a figura, sem nunca a envolver completamente. Do mesmo modo, diz Merleau-Ponty, é porque sempre percebo uma figura sobre um fundo que a atitude analítica pode ver ali semelhanças e contiguidades (M-P, p. 39, 1999a). É a própria percepção que permite supor as ideias de contiguidade e semelhança. A estrutura realiza-se na nossa experiência e todos os caracteres que o pensamento objetivo encontra para explicá-las, ele retira da própria percepção, desmonta o percebido para dar ao sensível aquilo que, de antemão, a experiência perceptiva já oferecia: a boa forma. Portanto, o erro de base do empirismo e do intelectualismo é não aderir à percepção e forjar um sentido secundário para o percebido, isto é, tomar por objeto o mundo objetivo que não é o primeiro.

A relação vivida na percepção é mais do que uma associação, é uma junção essencial dada, de imediato, como uma estrutura, como arranjo espontâneo das partes. Aí está, juntamente com Husserl, a grande contribuição da Gestalttheorie, essa densidade de sentido que emana do pré-reflexivo, mas sobre o qual somente a filosofia merleaupontyana voltou-se, conservando-se nela, sem esperar outra coisa 
além da apreensão do seu sentido. Trata-se da vida pré-científica da consciência, onde as gestalten realizam-se, trata-se do lócus determinado e, ao mesmo tempo, aberto de uma noção de estrutura fenomenológica que a Gestalttheorie não explorou.

Na primeira parte da PHP, até o capítulo sobre o campo fenomenal, a estrutura garante a identidade do ato de perceber. Se a função constituinte da consciência ainda pairava incólume sobre o campo fenomenal, dadas as consequências dos últimos capítulos da SC - aquele índice de subjetivismo de matriz criticista -, essa nova releitura da percepção como estrutura leva Merleau-Ponty a descobrir a lógica autóctone que explica a nossa adesão ao imediato, ao campo fenomenal: nem processos subjetivos, nem posse de "coisas" como invariante universal. MerleauPonty retoma a distinção, a separação entre a psicologia introspectiva e a psicologia fenomenológica como signo da passagem de uma filosofia da consciência para uma filosofia da percepção, como conversão do campo transcendental em fenomenal. A psicologia introspectiva - de matriz kantiana - converteu a consciência na zona de ser que deve ser explorada conforme o modelo das ciências naturais. O psicólogo instrospectivista acredita encontrar nos dados da consciência o sentido do ser e faz isso "sem colocar em questão a existência absoluta do mundo em torno da consciência" (M-P, p. 92, 1999a). Nessa perspectiva, ele encontra, nos dados da consciência, os motivos, as razões e o sentido lógico do mundo objetivo. Já a psicologia fenomenológica, fundada na noção de estrutura, reuniu o transcendental à experiência e colocou em questão: "se este mundo imediatamente presente, o único que conhecemos, não é também o único do qual convém falar" (M-P, p. 93, 1999a). Contudo, é preciso considerar uma dificuldade de explicitação desse campo fenomenal dessa redução radical -, aberto a partir da noção de estrutura como sentido imanente. Finalmente, Merleau-Ponty redescobre, na noção de estrutura, aquilo que não foi realizado ou levado em conta pela Teoria da Gestalt. Uma filosofia da estrutura só é possível se afastarmos dessa noção as ideias de coisas, de lei, de razão e, certo modo, todas as perspectivas substancialistas. A estrutura, pensada como figura e fundo, como sentido imanente ao vivido, não é encontrável fora da experiência, nem antes e nem depois da experiência, nem na consciência e nem nas coisas, ela é o dado nascente da experiência, contemporânea ao perceber e ao aparecer:

Mas, se a Gestalt pode ser expressa por uma lei interna, essa lei não deve ser considerada como um modelo segundo o qual se realizariam fenômenos de estrutura. Sua aparição não é o desdobramento, no exterior, de uma razão preexistente. Não é porque a forma realiza um 
certo equilíbrio, resolve um problema máximo e, no sentido kantiano, torna possível um mundo que ela é privilegiada em nossa percepção; ela é a própria aparição do mundo e não a sua condição de possibilidade, é o nascimento de uma norma, é a identidade entre o exterior e o interior e não a projeção do interior no exterior. Portanto, se ela não resulta de uma circulação de estados psíquicos em si, não é mais uma ideia. A Gestalt de um círculo não é a sua lei matemática, mas a sua fisionomia ( M-P, p. 95, 1999a).

A estrutura, como o texto acima estabelece, só é modelo para a percepção porque permanece fora de toda objetivação substancialista. $\mathrm{E}$ a percepção, por seu turno, só se constitui como estrutura, enquanto totalidade, enquanto sentido imanente, apreendida num contexto figura e fundo. A estrutura é a instituição de um sentido dado num acontecimento, no encontro do cogito com as coisas. Nessa perspectiva, mesmo na primeira parte da PHP, Merleau-Ponty já reafirma uma diferença importante em relação à Teoria da Gestalt. Esse deslocamento está, primeiro, no fato de que, na PHP, a estrutura figura e fundo não foi naturalizada, não é uma forma dada como um ente correspondente ao substrato fisiológico. Depois, Merleau-Ponty não parte da Gestalt para explicar a percepção, ele faz o caminho inverso e redescobre a estrutura, como já disse acima, como sentido imanente e, ao mesmo tempo, aberto no campo perceptivo. Essa diferença, não considerada nas leituras de Barbaras e Descombes, já indica o sentido singular da noção de estrutura adotado por Merleau-Ponty: um acontecimento perceptivo a que não pertence a ordem do ser - do em si e do para-si - mas do perceber.

Contudo, pode-se argumentar, em acordo com a crítica de Descombes, que até esse momento a estrutura não deixa de operar como um modelo, como uma representação do percebido. Portanto, Merleau-Ponty quase não avançou em relação à teoria da Gestalt, pois romper com o isomorfismo seria insuficiente, seria apenas um desvio, uma espécie de readequação do transcendental ao fenomênico que ainda manteria a sua filosofia muito longe de uma filosofia da estrutura. Nesse caso, é preciso considerar que a noção de estrutura deixa de operar unicamente como modelo da percepção quando é estendida para as categorias que dão sentido à condição do ser-no-mundo. Essa perspectiva encontra o seu correlato nas noções de esquema corporal, espacialidade, temporalidade e liberdade.

"O corpo é o veículo do ser-no-mundo". Essa tese merleau-pontyana bem que poderia ser o emblema do corpo próprio. De imediato, ela já me orienta a não tomar o corpo como um objeto partes-extra-partes e indica que é pelo corpo que se compreende o que é um cogito, o que é o mundo e o que significa ser-no-mundo. O corpo é veículo, carne do ser-no-mundo, porque, quando me volto a ele, encontro, primeiramente, um ser que é 
indistintamente corpo e alma, isto é, no corpo próprio não há lugar para o dualismo do em-si e do para-si. Um exame mais detalhado desse corpo, o que significa tão somente deixar-se pensar por ele, mostra que, diferente dos objetos, o meu corpo "é uma presença que nunca me deixa". Mas esse corpo próprio, extensão, pensamento e presença do meu ser é, também, fugidio. Perpetuamente, o corpo próprio reelabora uma unidade que me envolve muito antes que a minha consciência possa elaborar qualquer tese sobre ele. O corpo próprio recusa um olhar integral, uma percepção devoradora de todas as suas partes ou uma representação unívoca; tudo que tenho dele é uma certeza indissociável de um recôndito de carne que esconde outro: "Sua permanência não é de uma permanência no mundo, mas uma permanência ao meu lado" ( M-P, p. 134, 1999a). Depois, a síntese inacabada do corpo é da ordem do tempo, pois quando toco ou vejo o corpo próprio, sou incapaz de apreender um sentido separado do tocar e do ver, como se toda a verdade do corpo estivesse presa nesse momento do tocar e do ver. Mas o meu corpo, diferente das coisas, tem esse mágico poder de ser sentiente e sentido. É justamente essa organização ambígua de tocante e tocado que o faz "surpreender-se a si mesmo", ele tenta tocar-se tocando e realiza um tipo de reflexão que não é da ordem da consciência. É impossível pensar o pensando-se de si mesmo, como também não experimentamos, ao mesmo tempo, no mesmo toque entre as próprias mãos a certeza indistinta entre mão que toca e aquela que é tocada. Mesmo diante do espelho o corpo nunca vê o olhar que se vê. Além do mais, o corpo próprio é uma totalidade, no sentido de uma Gestalt fundada num saber afetivo, uma carne que se faz totalidade contemporaneamente a todas as expressões do sentir. Uma dor no pé é mais do que um sentimento localizado em uma extremidade que estaria longe do meu ser, é uma verdadeira dor localizada na carne ser, como a falta de um braço é uma modificação do meu-ser-no-mundo e do mundopara-o-ser. Se não fosse apenas isso, o corpo próprio é uma força que se projeta incessantemente para o mundo, é o agente do seu agir, tem em si o poder e o desejo de dirigir-se continuamente ao mundo. O corpo próprio, portanto, fornece o índice de uma certeza natural da minha existência, do início ao fim estou inelutavelmente preso ao mundo: "O corpo próprio está no mundo assim como o coração no organismo; ele mantém o espetáculo visível continuamente em vida, anima-o e alimenta-o interiormente, forma com ele um sistema" ( M-P, p. 274, 1999a).

O corpo próprio, a sua permanência não vista e não tocada à maneira como manejamos os objetos, é o fundo que permite aceder a todos os objetos. A presença ou ausência dos objetos exteriores são apenas variações no interior de um campo de presença primordial, de um domínio perceptivo sobre os quais meu corpo tem potência. Portanto, é 
a estrutura figura e fundo que parece ordenar a relação de presença do corpo - enquanto veículo do ser-no-mundo - com as coisas e com o outro.

A espacialidade do corpo - diferente das coisas - é sempre envolvimento e as regras da física ordinária não dão conta dessas relações. Na física, as coisas estão dispostas conforme os caracteres do espaço geométrico (antes, depois, abaixo, ao lado, acima). No corpo próprio, a espacialidade é um sistema de relações no qual os órgãos não estão justapostos, mas expressam uma unidade no sentido de uma estrutura. Aqui, não temos uma espacialidade de posição, mas sempre de situação. Essa posse indivisa, essa experiência perpétua de envolvimento forma o que Merleau-Ponty denomina de esquema corporal.

O esquema corporal foi concebido, antes de tudo, como um processo de associação. Para as teorias clássicas da psicologia e do comportamento, ele é o resultado de uma aprendizagem, seria algo como uma consciência em formação capaz de guardar os dados da experiência corporal. Essa memória, que formaríamos conforme a passagem do tempo, resultaria da combinação das experiências interoceptivas, exteroceptivas e dos dados cinestésicos em uma unidade de consciência do próprio corpo. $O$ esquema corporal seria, portanto, uma espécie de saber empírico pelo qual se estabelece um domínio pensante sobre a partes do corpo.

Uma segunda noção de esquema corporal remonta a Teoria da Gestalt: “... uma tomada de consciência global da minha postura no mundo intersensorial, uma forma no sentido da Gestaltpsychologie" (M-P, p.145, 1999a).

Essas duas definições estão longe de esgotar a ideia esquema corporal. A concepção associacionista incorre no erro clássico de tomar um sentido prévio já instalado no corpo por um entendimento a posteriori, na medida em que nega a unidade espacial e intersensorial do corpo próprio em proveito de um processo de associação. O esquema corporal, a nossa unidade carnal pré-predicativa, precede qualquer pensamento sobre si mesmo: "(...) a unidade intersensorial ou a unidade sensoriomotor do corpo são, por assim dizer, de direito" (M-P, p.145, 1999a).

A definição da Gestaltpsychologie para o esquema corporal, não muito diferente da primeira, também estaria ultrapassada pelo desenvolvimento da própria psicologia. Não se trata, nesse caso, de negar que o esquema corporal é uma forma, mas de esclarecer esse sentido no domínio da redução fenomenológica aberta no espaço primordial que envolve o corpo e as coisas. O esquema corporal compreende-se por uma noção mais radical de estrutura do que a tese de uma totalidade que não se resume à soma das partes. O esquema corporal é o saber pré-objetivo sobre cada parte do corpo e sobre a presença do corpo no mundo, um saber sobre a espacialidade do corpo próprio contemporâneo ao nascimento do 
corpo e ao aparecimento das coisas. O esquema corporal nasce do valor que o corpo encontra em si mesmo diante das solicitações e demandas do mundo: "o meu corpo aparece como postura em vista de uma certa tarefa atual ou possível" (M-P, p. 146, 1999). Para exemplificar melhor esse entendimento espacial da ordem da existência - das coisas e do corpo portanto, do lugar do corpo do mundo, não mais útil do que recuperar a bela análise sobre o jogador e o campo de futebol da SC:

O campo de futebol não é, para o jogador em ação, um 'objeto', ou seja, a palavra ideal que pode dar lugar a multiplicidade indefinida de vistas perspectivas e permanecer equivalente sob essas transformações aparentes. É percorrido por linhas de força (as linhas laterais, as que limitam a meia lua), articulado em setores (por exemplo, os buracos entre os adversários) que impõe certo modo de ação, a desencadeiam e exigem como à revelia do jogador. O campo não lhe é dado, mas está presente para ele como termo imanente das suas intenções práticas, ele e o jogador são um só corpo e jogador sente, por exemplo, a direção do gol tão imediatamente quanto a vertical e a horizontal de seu próprio corpo. ( M-P, p.263, 2006)

Jogador e campo formam "um só corpo", pois a comunicação entre ambos é da ordem do sentir e não do pensar. O corpo, ao mesmo tempo em que sente, transforma a espacialidade objetiva de posição em uma espacialidade de situação, dada no domínio da existência e não do pensamento objetivo. A comunicação é imediata, os signos do campo impõem-se ao corpo do jogador, como se as linhas, por exemplo, deixassem de apenas marcar uma certa divisão e se convertessem em signos que somente podem ser interpretados e expressados como movimento do corpo destinado a responder às solicitações do campo e aos objetivos do jogo. Assim, todo movimento encontrado no corpo é a expressão de um saber pré-reflexivo nascido do encontro do corpo com as coisas. Corpo e campo compõem um único espaço, não estão lado a lado, nem frente a frente, mas envolvidos em uma única atmosfera. Mas essa atmosfera é pervertida pelas tarefas do corpo, pelo projeto do ser, pela própria arquitetura do espaço que não mais se apresenta como sistema de coordenadas organizadas em três dimensões, mas como um solo dinâmico que, incessantemente, comunica-se e demanda ao corpo uma postura ativa. No que concerne à espacialidade, estabelece a PHP ... "o corpo próprio é o terceiro termo, sempre subentendido, da estrutura figura e fundo, e toda figura sempre se perfila sobre o duplo horizonte do espaço exterior e do espaço corporal" (M-P, p. 145, 1999a). Nessa articulação estrutural entre o corpo próprio e o espaço, os signos da distância são afetivos, estão no domínio da vida intencional. O desejável, o manipulável, o vital, o compreensível, o visado e o tocado dão as medidas da distância 
construídas pela presença do corpo no mundo. A proximidade, antes de ser uma medida em si mesma, é sentida pelo corpo, e dada pela disposição e pelas solicitações das coisas no mundo. O esquema corporal, portanto, aparece como centro de uma subjetividade não tética, é o saber pré-reflexivo sustentado por um sistema de correlações, sempre orientado a alcançar esse espaço de situação - vital e afetivo - onde o pensamento objetivo só enxerga coordenadas geométricas:

O espaço corporal pode distinguir-se do espaço exterior e envolver suas partes em lugar de desdobrá-las, porque ele é a obscuridade da sala necessária à clareza do espetáculo, o fundo do sono ou a reserva de potência vaga sobre os quais se destacam o gesto e sua meta, a zona de não-ser diante da qual podem aparecer seres precisos, figuras e pontos. (M-P, p.146-147, 1999a).

Merleau-Ponty mantém o paradigma figura e fundo na hora de explicar a noção de esquema corporal e de espaço de situação. Essa estrutura é o equivalente existencial da condição do ser no mundo, da situação do corpo no mundo. O meu corpo está no mundo, mas não é o mundo. Ao mesmo tempo em que ele está separado do mundo, das coisas, das paisagens, é sustentado por esse mundo, está ligado à paisagem, pois, sem esse fundo, ele não seria visível, não seria encontrável. A estrutura figura e fundo não remonta a uma relação de conjunto como de contido e conteúdo, deixa de operar como modelo de percepção para significar presença, pois o esquema corporal não é um saber de si, das partes do próprio corpo encerrado em si mesmo, mas um saber disso em relação ao mundo, ou melhor, sobre a espacialidade do corpo e do mundo como dois termos intraimplicados. Se o meu corpo, conforme estabelece a PHP, “... pode ser uma forma e se pode haver diante dele figuras privilegiadas sobre fundos indiferentes, é enquanto ele está polarizado por suas tarefas, enquanto existe em direção a elas, enquanto se encolhe sobre si para atingir sua meta, e o esquema corporal é finalmente uma maneira de exprimir que o meu corpo está no mundo" (M-P, p. 146-147, 1999a).

Retomando as conclusões sobre as patologias motoras e cognitivas de Schneider, o esquema corporal é tomado como um sistema prático que une ao saber antipredicativo sobre o próprio corpo o sentimento perpétuo de uma ligação estrutural com o mundo. A patologia motriz de Schneider dissocia o pegar e o mostrar: "Um doente a quem se pede que mostre com o dedo uma parte do seu corpo, por exemplo, o nariz, só consegue se lhe permite pegá-lo" (M-P, p. 150, 1999a). Essa diferença entre pegar e mostrar está na base da distinção entre o espaço nascido do esquema corporal e o espaço objetivo, pois é semelhante à distinção entre movimentos abstratos (visam ao espaço virtual) e concretos, entre o atual e o virtual. 
Quando recebe um estímulo qualquer - uma agulhada no braço, por exemplo -, Schneider somente é capaz de identificar o local do estímulo se puder alcançá-lo posando a própria mão no local dolorido. Ele é incapaz de identificar o local exato da agulhada no seu corpo, mostrando ou dizendo algo como: acima do joelho, no antebraço esquerdo etc. Schneider somente executa movimentos e localiza no seu corpo os estímulos que se ligam ao complexo vital da sua existência; para ele, o espaço só existe a partir de situações práticas. Schneider não pensa, não localiza o virtual, ele mantém-se inteiramente no espaço concreto no fundo de movimento dado para alguém que perdeu o sentido do espaço simbólico, pois a morbidade de Schneider é um enfraquecimento do esquema corporal em benefício das relações vitais. Essa patologia de Schneider não revela apenas uma perda de função, mas uma desorganização encontrada no esquema corporal e, por consequência, na relação de conjunto do doente com o mundo. A patologia não se explica simplesmente pela perda de dados táteis e visuais, mas está ligada à vida prática do sujeito, a perda de um referencial simbólico, de um espaço virtual, ao enfraquecimento do corpo para esboçar um comportamento fora do habitual. O corpo perdeu, em certa medida, uma subjetividade motora, ele não está integrado ao espaço mas aderido ao meio, como uma figura. O corpo de Schneider é quase inteiramente sem um fundo, carece de uma liberdade concreta, dessa que é capaz de por-se em situação:

Abaixo da inteligência enquanto função anônima ou enquanto operação categorial, é preciso reconhecer um núcleo pessoal que é o ser do doente, sua potência de existir. É ai que reside a doença. Schneider ainda gostaria de ter opiniões políticas e religiosas, mas sabe que é inútil tentar. Ele precisa contentar-se com crenças grosseiras, sem poder exprimi-las. Ele nunca canta ou assobia por si mesmo... nunca toma iniciativa sexual. Nunca sai para passear, mas sempre da uma caminhada (M-P, p. 188, 1999a).

Sem a doença, o comportamento é uma forma que integra os dados táteis aos visuais. Já no doente, o déficit de cinestesia, de acordo com os apontamentos de Goldstein, revela uma sensibilidade tátil em estado puro. O comportamento perdeu sua fisionomia de estrutura, explica-se por relações pontuais, pela sensação pura do tato, pois, para poder localizar o próprio corpo, é preciso que uma causa material intervenha, o toque. Para Schneider, o campo perceptivo perdeu a plasticidade, não apresenta uma história como um conjunto, como um todo significativo, apenas como sucessão de fatos. O presente é somente aquilo que é imediatamente dado, a fala do outro precisa ser interpretada metodicamente. É a base temporal que está afetada, Schneider precisa sempre de movimentos 
preparatórios, mediatizados para dar uma resposta, é meticuloso e incapaz de representar e entrar em uma situação fictícia, não separa uma adivinhação de um problema, "o futuro e o passado são prolongamentos encolhidos do presente. Ele perdeu 'nosso poder de olhar segundo um vetor temporal'" (M-P, p. 189, 1999a).

Essa motricidade operante que falta a Schneider resulta de um déficit da intencionalidade original nascida no esquema corporal, no domínio imediato do eu posso e não do eu penso. O esquema corporal como um sistema de equivalências amplia o campo de experiências da vida pessoal além dos procedimentos analíticos. O esquema corporal não é apenas uma experiência do corpo, um invariante formado no desenho fisiológico do corpo, mas do meu corpo no mundo. É a consciência primordial da presença do corpo próprio, do seu movimento e das solicitações do mundo e do outro que tornam possível formar com o mundo uma estrutura que se une à percepção. A noção de esquema corporal alonga o sentido da estrutura da percepção do mundo para a presença no mundo. Mesmo antes de ser um acontecimento perceptivo, a estrutura espacial - na forma do espaço primordial nascido do esquema corporal - é o termo fundante que me liga perpetuamente a um mundo mais rico do aquele descrito pela ciência.

Se a percepção é a estrutura de contato que torna possível apreender o mundo sensível, se o espaço primordial, nascido do esquema corporal, é a estrutura da minha presença que me liga às coisas, a temporalidade é a estrutura que unifica à experiência do perceber a condição de estarno-mundo, pois a síntese espacial e a do objeto - a unidade dos perfis - são fundadas no tempo: "As coisas coexistem no espaço porque estão presentes ao mesmo sujeito perceptivo e envolvidas na mesma onda temporal" (M-P, p. 371, 1999). Mas o que seria esse envolvimento temporal? Por que o tempo seria uma espécie de estrutura das estruturas? O que faz do tempo uma estrutura e não algo semelhante ao que encontramos no kantismo, por exemplo, uma categoria a priori da experiência sensível?

Diferente de Kant, Merleau-Ponty descreve a experiência de um tempo original dado num campo de presença no qual o corpo próprio comunicase interiormente com tempo. Além disso, enquanto uma estrutura primordial dada no campo transcendental da experiência perceptiva, o sentido das dimensões temporais não precede a intencionalidade operante que nasce com o corpo próprio. Todas as nossas experiências dispõem-se no tempo, assim como a própria subjetividade faz-se no tempo: "Analisar o tempo não é tirar consequências de uma concepção pré-estabelecida de subjetividade, é ter acesso através do tempo, à sua estrutura concreta" (M-P, p. 550, 1999a). A percepção abre-se para um campo de presença com duas dimensões originais: espacial e temporal. 
"Quanto à relação entre o objeto percebido e minha percepção, ela não os liga no espaço e fora do tempo: eles são contemporâneos" (M-P, p. 357, 1999a). Assim, o cogito habita uma totalidade espaço-temporal e todo o saber pré-reflexivo do esquema corporal é "secretado" no tempo. A dimensão temporal permite compreender a subjetividade e a inerência espacial ao retomar a existência vivida - todos os atos de percepção como continuidade: "Eu possuo, eu tenho o objeto distante ... assim como 'ainda tenho em mãos' o passado próximo sem nenhuma deformação, sem recordação interposta" (M-P, p. 358, 1999a). Portanto, a relação entre o cogito e o tempo é diferente do que aquela enunciada por Kant. Enquanto, para Kant, "a temporalidade (...) é a forma do sentido interno, porque ela é o caráter mais geral dos fatos psíquicos"(M-P, p. 549, 1999), para Merleau-Ponty, o tempo original não prepara e não enforma a experiência sensível, ele é contemporâneo à experiência, o tempo vivido não precede o cogito, ele nasce com o esquema corporal.

Merleau-Ponty, assim como Bergson, quer escapar das definições clássicas do tempo como instantes que não passam, ou como sucessão de agoras ou, ainda, da concepção do tempo como uma unidade sintética supratemporal fundada em um sujeito atemporal, como encontramos em Kant. Bergson, ao seu modo, supera essas concepções pensando o tempo como duração, encontrando na ideia de continuidade a significação última de uma temporalidade que não se reduz à noção de passagem. Para Bergson, a duração, de modo geral, é a forma dos nossos estados de consciência que se abstêm de separar as experiências entre momentos presentes e ausentes. A duração, enquanto forma pura da temporalidade, é sucessão, continuidade e constituição de um todo que unifica o tempo na sua passagem, conforme podemos ler no segundo capítulo de Durée e Simultanéité:

Escute a melodia fechando os olhos e somente pense nela, não justapondo mais sobre um papel ou sobre um teclado imaginário as notas que você conservava assim uma por uma, pela qual você aceitava então a passagem simultânea e renunciava a sua continuidade fluída no tempo para se congelar no espaço: você achará inteira, indivisível a melodia ou a porção da melodia que você teria substituído pela pura duração. Ora, nossa duração interior, considerada do primeiro ao último momento da nossa vida consciente, é qualquer coisa como essa melodia. (BERGSON, p. 47, 2009)

No entanto, para Merleau-Ponty, ao sustentar que os instantes fundem-se na consciência, Bergson não ultrapassou verdadeiramente o problema da dispersão, mas o camuflou sobre uma atividade sintética da consciência, reproduzindo, desse modo, os prejuízos clássicos sobre a 
temporalidade. Como se Bergson refundasse, no terreno da psicologia do eu empírico -, as operações do cogito desdobradas no transcendental kantiano. Bergson teria retirado a continuidade do interior do tempo e transferido para a subjetividade. Desse modo, Bergson, nas palavras de Merleau-Ponty, "estava errado em explicar a unidade do tempo por sua continuidade, pois isso significa confundir passado, presente e porvir sob o pretexto de que se caminha de um para o outro por transições insensíveis, e enfim significa negar o tempo. Mas ele tinha razão em apegar-se à continuidade do tempo como a um fenômeno essencial. É preciso apenas elucidá-lo" (M-P, p. 563, 1999).

Nesse caso, qual é o sentido dessa continuidade que Merleau-Ponty entende como essencial? O tempo como significação é a estrutura permanente que reúne a multiplicidade dos perfis dado na percepção a uma unidade de sentido e, ainda, confere à presença - a ligação do corpo com o mundo - o seu sentido existencial. Não é o tempo que nos separa das coisas, da juventude e da própria vida, pois o tempo não escoa. Não é o tempo que decreta a nossa morte, ao contrário, o tempo é responsável pela permanência, pela apreensão do escoamento perpétuo que sentimos na pele. Não se trata de negar o escoamento como movimento de passagem, por exemplo, da vida à morte. As coisas esvaem-se, perdemse como a areia entre os dedos, mas isso não é o tempo, ou pelo menos não é a imagem do tempo que encontramos na leitura de Merleau-Ponty.

Como bem estabeleceu Carbone, em uma interpretação que liga a tese de Merleau-Ponty sobre a temporalidade à obra de Proust, ${ }^{6}$ a reflexão sobre a temporalidade busca alcançar, entre a consciência perceptiva e as coisas, uma continuidade imanente em que a diversidade permaneça como tal. Essa articulação entre imanência e transcendência, unidade e diversidade, está, antes de tudo, dada na experiência do tempo original fundada nos dois horizontes de passado e futuro - protensão e retenção - já descritos por Husserl desde Lições para uma fenomenologia íntima do tempo (1904). Merleau-Ponty, nas palavras de Carbone, "retoma essa ideia de uma implicação do passado - e, simetricamente, do futuro - no presente da noção husserliana de intencionalidade operante (fungierende Intentionalität), isto é, a relação antipredicativa que, unindo o indivíduo ao mundo, inaugura o tempo vivido" (CARBONE, p. 35, 2001).

Os horizontes temporais - retenções e protensões - nascem do presente e formam, em conjunto, um único instante no mundo, assim como cada passado está encerrado imediatamente no passado recente

6 Conforme Merleau-Ponty escreveu - e como já tivemos ocasião de lembrar - o projeto fenomenológico e o de Proust reúnem-se "pelo mesmo desejo de compreender o significado do mundo ou da história em estado nascente" (CARBONE, p. 41, 2001). 
que lhe sucedeu. As protensões e as retenções estão dadas no campo perceptivo como intencionalidades operantes que garantem a duração e a passagem, o passado e o porvir. Enquanto a retenção, conforme tinha enunciado Husserl, alcança o passado em sua ecceidade recente, mas já passada, a protensão, pensada a partir da noção heideggeriana de transcendência, precipita-se no presente, abre um horizonte de futuro no presente. Contudo, como se dá o movimento do tempo vivido que experimentamos? Essa transcendência? Por que esse movimento não é a própria dissolução do tempo? Se existe passagem como é possível conservar uma unidade?

Para não correr o risco de "matar" o tempo, deve-se buscar uma temporalidade que comporte a passagem e a própria duração como um acontecimento estrutural, isto é, compreender "a noção de tempo, não como um objeto de nosso saber, mas como uma dimensão do nosso ser" (M-P, p. 557, 1999a). Para Merleau-Ponty, o tempo não é como o riacho, uma substância fluente, uma sucessão de instantes, pois essa tese do tempo como passagem só é possível para um observador que não experimenta o tempo vivido, isto é, um sujeito que ocupa um certo posto colocado no espaço e no tempo objetivos: "O tempo supõe uma visão sobre o tempo" (M-P, p. 551, 1999). Por isso mesmo, o tempo não é uma conservação psíquica ou fisiológica na forma de uma consciência do passado, pois, quando evocamos a memória, todas as lembranças não trazem de volta uma experiência já vivida, são antes traços do presente. Do mesmo modo, não podemos construir o futuro com conteúdos da consciência. A passagem é da ordem da temporalidade e não da consciência. Portanto, o tempo não é, como queria Bergson, uma ideia complexa traduzida sobre o conceito de duração. O tempo, enquanto a estrutura significativa da condição do ser-no-mundo, encontra, na lógica da sucessão das dimensões vivenciadas pelo cogito, o sentido da passagem e da duração. Estou, conforme essa lógica, envolvido em uma vivência sempre atual das dimensões espaciais e temporais: no presente preso a um passado que não me larga e, ao mesmo tempo, ligado a um futuro que se anuncia constantemente na atualidade vivida. Assim como as coisas e os instantes estruturam-se entre si e estabelecem, como descreve Merleau-Ponty, "um mundo através desse ser ambíguo que chamamos de subjetividade, só podem tornar-se co-presentes de um certo ponto de vista e em intenção" (M-P, p. 446, 1999a). O passado e o futuro são presenças sólidas e vivas que experimentamos não como ilusão, sonho, imaginação, ou qualquer espécie de projeção psicológica. O passado distante, como também o passado recente, tem uma ordem e uma posição em uma única estrutura temporal. Quando penso na minha infância, retomo a estrutura do tempo, e entre esse passado, 
agora, um verdadeiro presente retomado, eu recoloco um duplo horizonte de temporalidade: passado e porvir. Todo esforço de memória - "um esforço para reabrir o tempo" - comporta um porvir e um horizonte de passado, tem uma espessura de tempo. As dimensões do tempo, como os objetos da percepção, são pensadas como intencionalidades que me ancoram em uma circunvizinhança temporal: "Eu antes conto com uma circunvizinhança do que percebo objetos" (M-P, p. 558, 1999a). O passado e o futuro estão presentes na minha experiência do tempo antes de eu propriamente voltar-me a eles. Assim como, de modo análogo, conto com objetos em torno de mim que não são absolutamente vistos, mas são sentidos na medida em que "habitam" um mesmo ambiente. Portanto, o passado e o futuro não são funções da consciência; são, na maior parte das vezes, a consciência das dimensões contínuas e distintas do tempo que sentimos presentes no nosso campo transcendental, como, de modo análogo, sentimos a presença de um precipício no fundo de um vale. $\mathrm{Na}$ experiência do tempo, apreendo o que é a passagem, o antes e o depois, como um fenômeno de permanência, pois o passado e o futuro são manifestações de uma única vaga temporal. Entre as três dimensões, há uma unidade natural, formam a espessura da temporalidade e, de certo modo, são apreendidas, novamente, pela estrutura de conjunto figura e fundo, pois, na experiência do tempo vivido, essas dimensões estão dadas, conforme Merleau-Ponty, "como o verso de uma casa que vejo a fachada, ou como o fundo sob uma figura" (M-P, p. 557, 1999a).

O passado, o presente e o futuro estão ancorados e formam um único tempo. O sujeito não é a consciência constitutiva de presente, ou mesmo o seu cárcere. Se entre as dimensões do tempo existe uma unidade, ela é estrutural. A estrutura do tempo recai num esquema dialético de solicitações e motivações semelhante àquele que descrevemos acerca do esquema corporal. As dimensões do tempo, concebidas de modo semelhante ao esquema cultivado entre o corpo e as coisas, estão em comunicação perpétua entre si. O presente, por exemplo, projeta-se em direção a um passado e a um futuro e reconhece-os no lugar - no tempo -, onde eles estão e são significativos. Mais do que um momento ou uma medida, o tempo é um "ambiente" orgânico, pois vivo nele, detenho-me nele e, ainda, passo por ele. E, portanto, vivemos o tempo como uma "atmosfera" em que experimentamos a passagem do presente ao virtual sem nunca confundi-los, no qual provamos a unidade entre a multiplicidade sem nunca anulá-las e, a partir do qual, elaboramos a significação da presença e da ausência porque conservamos vivos os signos da espacialidade.

Desse modo, o tempo explica a noção de abertura, a condição ambígua do ser no mundo, o seu inacabamento, pois o presente é esse duplo 
horizonte de retenção e protensão. O horizonte - seja de passado ou de futuro - comunica-se com o meu presente, sustenta-se diante do meu olhar como um corpo celeste que flutua preso e não ao sólido organizado, mas ao conjunto de forças invisíveis que estruturam o espaço, como um fundo apreendido como carne invisível porque envolve uma figura. A temporalidade, de certo modo, perverte a relação figura e fundo. É o fundo que é aberto pelo centro, é a figura que torna o fundo visível, como são os horizontes de protensão e retenção abertos pelo presente; por isso mesmo, a memória é uma fissura no presente e não o retorno a um passado: "Só se compreende o papel do corpo na memória se a memória é não a consciência constituinte do passado, mas um esforço para reabrir o tempo a partir das implicações do presente" (M-P, p. 246, 1999a).

A consciência e o corpo estão enraizados no tempo como, também, não deixam de ser um projeto universal e uma visão povoada de uma unidade de sentido, mas sempre num determinado contexto temporal. A consciência, por mais sólida e íntegra que possamos imaginá-la, nunca será um eu constituinte como uma razão pura ou, ao contrário, um aparelho do entendimento capaz de interpretar os signos de uma experiência acabada. Toda a consciência encontra-se, desde sempre, envolvida no próprio eu e, também, nos apelos do ambiente. Através da estrutura da temporalidade são as coisas, o outro e o próprio eu, perceptíveis no seu engajamento estrutural. Por isso, Merleau-Ponty fala de uma síntese passiva do tempo, que experimentada pela consciência é, todavia, realizada aquém dela:

Falando em síntese passiva, queríamos dizer que o múltiplo é penetrado por nós e que, todavia, não somos nós que efetuamos a sua síntese. Ora, a temporalização, por sua própria natureza, satisfaz essas duas condições: com efeito, é visível que eu não sou o autor do tempo, assim como eu não sou o autor dos batimentos do meu coração, não sou eu quem toma a iniciativa da temporalização; eu não escolhi nascer e, uma vez nascido, o tempo funde-se através de mim, o que quer que eu faça. E todavia este jorramento de tempo não é um simples fato que eu padeço, nele posso encontrar um recurso contra ele mesmo, como acontece em uma decisão que me envolve ou em um ato de fixação conceptual. Ele me arranca daquilo que eu ia ser, mas ao mesmo tempo me dá o meio de apreender-me à distância e de realizar-me enquanto eu. (M-P, p. 573, 1999a)

É na vivência original e indissociável da espacialidade e da temporalidade que a síntese perceptiva repousa, realiza-se e, desse modo, permite a subjetividade desvelar-se como um ser situado e aberto. Vivemos, como as palavras do texto merleau-pontyano acima apontam, como o próprio tempo: na permanência e na fugacidade. Afinal, o tempo 
"me arranca daquilo que eu ia ser e me dá o meio de aprender-me à distância e de realizar-me enquanto eu". Temos a posse das coisas, mas elas também são, ao mesmo tempo, perenes, oblíquas e fugazes. $\mathrm{E}$, como o tempo que vive em mim e nas coisas, tenho sua experiência completa e sou possuído pelo tempo sem jamais percorrê-lo ou preserválo integralmente, pois ele também não se permite uma posse integral e definitiva e, naturalmente, é movente, transitório e, ambiguamente, permanente. A relação do sujeito com o tempo é a do coração com o corpo. Nasci no tempo, estou ligado a ele, como o meu corpo e a minha vida não existem sem meu coração. Mas compreendo o tempo na mesma medida em que me movimento e desloco em função do meu coração. Não coloquei o coração em marcha - como não fiz com o tempo - mas marcho com ele, tenho o poder de acelerá-lo e até de fazê-lo parar, mas não tenho o poder de continuar sem ele. A imobilidade do tempo é, para a vida subjetiva, o que a imobilidade do coração é para o corpo objetivo. Assim, Merleau-Ponty concluiu que o exame do tempo "(...) ilumina as análises precedentes porque faz o sujeito e o objeto aparecerem como dois momentos abstratos de uma estrutura (grifo meu) única que é a presença" (M-P, p. 577, 1999a).

\section{Conclusão}

A filosofia da estrutura que encontramos na PHP encaminha-nos para duas novas interpretações da obra merleau-pontyana.

Primeiro, a consideração do pensamento nascente no interior da PHP como prelúdio de uma nova filosofia que apenas debutaria quase duas décadas após a publicação da PHP. A obra de Merleau-Ponty, certamente, não pode ser identificada como uma filosofia da estrutura no mesmo sentido da geração que o precedeu e, como bem estabeleceu Descombes, abriu uma nova paisagem filosófica:

A geração de 1960 renuncia aos ideais de um novo classicismo e de uma civilização orgânica que Merleau-Ponty defendia em 1960. Ela não acredita mais que a tarefa do século seja integrar o irracional a uma razão alargada. A tarefa agora é a desconstrução daquilo que mostra como princípio da linguagem dominante no Ocidente (a lógica da identidade) e a crítica da história considerada a partir de agora como um mito, isto é, uma solução eficaz, mas sem verdade, do conflito entre o mesmo e o outro. (DESCOMBES, p. 130, 1997)

A PHP representa um esforço de reencontrar a significação primordial que habita o irrefletido, busca no campo aberto pela redução o princípio que permitiria integrar o eu, as coisas e o outro como um sistema 
de equivalências que escaparia às antinomias do para-si e do em-si. Essa é a verdade resumida de uma interpretação - que também é de Descombes - e da qual não podemos fugir. Além do mais, a PHP fiel ao projeto da redução - e isso em acordo com Descombes - não desconstrói as aparências, não encontra, na superfície, a estrutura como aquele núcleo de sentido que ultrapassaria todas as formas de subjetividade em referência a um sistema de correlações objetivas como encontramos, por exemplo, na etnologia e na linguística.

Todavia, é preciso reconhecer que Merleau-Ponty, desde a SC, recolhe a estrutura para o interior da Filosofia, faz dela não apenas o índice de metodológico de um pensamento, mas a faz deslizar para o mundo, para o tempo e para existência. É preciso ler a PHP até o fim e encontrar o sentido da existência que emerge da condição do ser-nomundo pensado na estrutura liberdade-situação: "Há uma troca entre a existência generalizada e a existência individual, cada um recebe e dá." (M-P, p. 603, 1999a). A liberdade é o ponto primário, mas é vivida contra um background, um fundo de mundo, uma situação que é orgânica e é, também, histórica. Uma figura pode ser uma melodia diferenciada de um fundo harmônico, uma mancha vermelha sobre um fundo branco ou, como encontramos, no capítulo sobre a liberdade, um cogito que emerge sobre um fundo de existência generalizado: "Sou uma estrutura psicológica e histórica. Com a existência recebi uma maneira de existir, um estilo. Todos os meus pensamentos e minhas ações estão em relação com esta estrutura, e mesmo o pensamento de um filósofo não é senão um maneira de explicitar seu poder sobre o mundo, aquilo que ele é" (M-P, p. 611, 1999).

Uma segunda conclusão, talvez a única realmente forte, está na releitura da má ambiguidade presente do interior da PHP, aquele índice de cogito constituinte que retomaria para si o sentido do mundo, que parece ainda contaminar a filosofia merleau-pontyana, como ele próprio reconhece ${ }^{7}$. A estrutura, nas suas diferentes "formas", como percepção, como presença e, finalmente, como unidade de significação operada no interior da temporalidade indica, já na PHP, o esboço de um sentido que não é da ordem do em si ou do para-si, mas pertence à condição do ser-no-mundo. Ainda não podemos falar da estrutura como um tecido, mas, muito certamente, a renovação da Gestalt que Merleau-Ponty reclama no

7 Cf. "O estudo da percepção somente podia nos ensinar < uma má ambiguidade>, a mistura da finitude e da universalidade, da interioridade e da exterioridade. Mas existe, no fenômeno de expressão, uma boa ambiguidade, isto é, uma espontaneidade que realiza aquilo que parecia impossível, a considerar os elementos separados, que reúne em só tecido a pluralidade das mônadas, o passado e o presente, a natureza e a cultura" (M-P, p. 30, 2000) 
VI como parte de uma nova ontologia do sensível já encontra, na PHP, o seu esboço inicial. Na PHP - livre do realismo da Teoria da Gestalt e dos postulados intelectualistas concebidos na SC -, a estrutura deixou de ser uma coisa como também de representar o produto de integração entre ordens diferentes operadas por uma consciência perceptiva. Com a noção de estrutura, a intencionalidade operante - das nossas tomadas de posição diretas e incessantes - pode ser compreendida como ato originário de apreensão de um sentido que também é oferecido pelo mundo. Como apresentamos na discussão sobre o esquema corporal, a estrutura também nasce das coisas, pois o sistema de equivalências do corpo próprio é solicitado por um mundo que parece esboçar-se intencionalmente, assim como a nossa liberdade também se encontra "na nossa situação social e histórica". É preciso, além do mais, lembrar que o tempo é retomado pelo cogito, mas é também uma estrutura de três dimensões que o envolve, pois tudo o que retira do tempo é somente aquilo que próprio tempo oferta. A estrutura não apaga as diferenças entre a PHP e o VI, mas reconduz à reflexão fenomenológica em direção a uma ontologia, afinal a estrutura que reúne o percepiente ao percebido já é um tema da PHP. Por isso mesmo, ainda que não realize a reabilitação ontológica do sensível como é exigido no VI; na PHP, a estrutura, pensada a partir do paradigma figura e fundo, é o debut da ligação ontológica entre o sentiente e o sentido. Desse modo, talvez um pouco na contracorrente da leitura francesa de Merleau-Ponty, o reconhecimento de uma filosofia da estrutura no interior da PHP permita-nos a ler sua obra no sentido prospectivo da temporalidade tão bem elaborado, e ver, na PHP, algo mais do que simplesmente o desenho de uma filosofia como antípoda de um projeto ontológico. O reconhecimento da estrutura mostra-nos que não é má ambiguidade da PHP que suscita o projeto do VI, mas é o VI que se projeta na fenomenologia, assim como é o futuro que se precipita no passado.

\section{Referências}

BARBARAS, Renaud. Merleau-Ponty et la psychologie de la forme. In: Les Études Philosophiques, n. 57, p. 151-163, 2001/2. DOI :10.3917/leph.012.0151

BERGSON, Henri. Durée e simultanéité. Paris: Quadriege/PUF, 2009.

CARBONE, Mauro. La visibilité de l'invisible. Merleau-Ponty entre Cézanne et Proust. Hildesheim: Georg Olms Verlag, 2001.

DESCOMBES, Vincent. Le Même et L'Autre: Quarente-cin Ans de Philosophie Française ( 1931-1978). Paris: Les Éditions de Minuit, 2005.

KANT, Immanuel. Crítica da razão pura. Lisboa: Fundação Calouste Gulbenkian, 1985. 
KOFFKA, Kurt. Princípios da Psicologia da Gestalt. São Paulo: Cultrix, 1989.

KÖHLER, Wolfgang. Psicologia da Gestalt. Belo Horizonte: Itatiaia, 1980. . Psicologia. (Org. Arno Engelmann). São Paulo: Ática, 1978.

KÖHLER, Wolfgang. Gestalt psychology: an introduction to new concepts in modern psychology. New York: New American Library, 1947.

GOLDSTEIN, Kurt. The organism: a holistic approach to biology derived from pathological data in man I with a foreword by Oliver Sacks. New York: Zone Books', 1995.

MERLEAU-PONTY, Maurice. Oeuvres. Éditions Gallimard, Paris, 2010. . Parcours deux (1951-1961). Paris; Éditions Verdier, 2000. . A estrutura do comportamento. São Paulo: Martins Fontes, 2006. . Fenomenologia da percepção. São Paulo: Martins Fontes, 1999. . O visível e o invisível. São Paulo: Perspectiva, 1999.

\section{Endereço postal:}

Escola de Educação e Humanidades

Rua Imaculada Conceição, 1155 - Prado Velho

80215-901 Curitiba, PR, Brasil

Data de recebimento: 04/08/2013

Data de aceite: 07/10/2013 